\title{
CRIANÇA: OBJETO a LIBERADO?
}

\section{Glaucineia Gomes de Lima*}

RESUMO: Lacan (1968-69) abordou a criança como objeto a liberado. Assim, ela é capturada no gozo, drama em torno do qual a família se estrutura. Tais formulações são questionadas no texto que discute o lugar da criança como objeto de gozo nos tempos atuais. Parte-se da discussão sobre a sociedade da globalização, cuja lógica se orienta para a produção incessante de objetos de consumo, marcada pelo declínio dos ideais e o impulso ao hedonismo mortífero. O imperativo do consumo na sociedade globalizada não é sem conseqüências para a educação, que se guia pela lógica de educar para o mercado, empreitada que tem como efeito o fracasso escolar, um dos nomes do 'mal-estar' na educação. Desponta, entre educadores e educandos, apatia, tédio e indiferença no vazio em que parece ter se tornado o espaço escolar. Os efeitos de retorno do gozo incidem sobre o corpo das crianças, que é objeto de maus-tratos, violência, pedofilia e todo tipo de abusos. Assim, conclui-se questionando qual é o lugar para a escuta do sintoma, face ao imperativo de consumo e a ascensão do objeto, e as suas conseqüências para o apagamento da subjetividade da criança.

Palavras-chave: Criança; Sintoma; Gozo; Desejo

\section{CHILD: FREED OBJECT $a$ ?}

ABSTRACT: Lacan approached the child as a freed object $a$. Thus, the child is captured in pleasure, drama upon which family is structured. These formulations are questioned in the text that approaches child as the current object of pleasure. The departing point is the discussion on the globalized society which heads to the on-going production of consumer objects, labeled by the decay of ideals and its drive to a lethal hedonism. But the consumption imperative in the globalized society has its own consequences on education which entails the logic of instructing for the market, leading to an educational failure, also known as educational uneasiness. What emerges from educators and students is apathy, boredom and indifference in the emptiness that schools seem to have turned into. The results of the return of pleasure fall upon the victimized children's body, an object of violence, pedophilia and of every kind of abuse. Where should the symptoms be listened to in view of the peremptory consumption and the rise of the object, taking into account their effects on the erasing process of child's subjectivity is the concluding question.

Keywords: Child; Symptom; Pleasure; Desire

* Psicanalista; Doutora em Psicologia pela Universidade de São Paulo (USP) e Professora do Curso de Psicologia da Universidade Presbiteriana Mackenzie.E-mail: glaucigomes@uol.com.br 
Qual o lugar que a criança ocupa no "mal-estar" da civilização atual? Para abordar o tema em questão, partirei da afirmação de Lacan, em seu texto "Radiofonia" (1970, p. 411), em que ele se refere à ascensão ao zênite social do objeto $a$ : "Para isso, bastaria a ascensão do objeto $a$, pelo efeito de angústia provocado pelo esvaziamento com que nosso discurso o produz, por faltar à sua produção". O movimento de ascensão se iniciou há bastante tempo, tendo em vista que o zênite é o grau mais elevado e Lacan se referia a um efeito particular do mestre contemporâneo, o capitalista, que produz o objeto $a$ cavando a falta da mais-valia.

Lacan (2008) refere-se à passagem em que o capitalista não consegue deixar de rir, ao propor o contrato de trabalho. A apropriação da mais-valia é encoberta, inscrevendo-se no bolso do capitalista como valor excedente. Ele se apóia em Marx, que demonstra que o trabalho é comprado pelo capitalista pelo preço de mercado, o que produz um resto, uma parte suplementar que não é jamais paga. A produção de tal quantidade suplementar que não é paga ao trabalhador é chamada por Marx de maisvalia. Para Lacan (1970, p. 434), a mais-valia

É a causa do desejo, do qual uma economia faz o seu princípio: o da produção excessiva, insaciável, da falta-a-gozar. Esta se acumula, por um lado, para aumentar os meios desta produção como capital. Por outro lado, amplia o consumo, sem o qual essa produção seria inútil, justamente por sua inépcia em proporcionar um gozo com que possa tornar-se mais lenta.

$\mathrm{Na}$ teoria marxista, a mais-valia é extraída do trabalho, uma parte não-paga e jamais recuperada. Há um ganho do lado do capitalista e, em conseqüência, do lado do trabalhador se instaura uma perda. Os direitos do sujeito, o trabalhador, dos quais ela é extraída, são instantaneamente excluídos, pois o mercado opera tal subtração.

A homenagem que Lacan presta a Marx deve-se à invenção do sintoma e da mais-valia. O valor do trabalho que nunca é pago ao trabalhador é resultado da subtração do valor de uso do valor de troca. Ao embolsar a mais-valia, há um excedente produzido e jamais recuperado. Há uma perda de gozo definitiva. Na formulação lacaniana, a construção do objeto $a$ é homóloga à mais-valia. Aflalo (2008, p. 83-84) explicita:

O objeto a é uma falta primeira que engendra uma incessante recuperação de gozo, pois a defasagem não é reabsorvida. O sujeito é empresário do seu próprio desejo, e a renúncia pulsional, necessária ao estabelecimento do discurso nutre o supereu. A gula do supereu é estrutural, não é um efeito da civilização. Um mesmo circuito econômico vale no capitalismo e na pulsão: perda e retorno de gozo sintomático. 
Laurent (2007) afirma que o conceito lacaniano de objeto $a$ refere-se a uma parte de gozo que sobra como resto de uma operação de extração. O objeto também está em ruptura com o Outro, no que este tem de universal, mas, diferentemente do sujeito, localiza-se com relação a algo prévio ao Outro.

Desde meados do século XX, o mundo assiste a uma inflação do consumo, em uma sociedade que não cessa de produzir objetos. $\mathrm{O}$ avanço da ciência e da tecnologia convive, paradoxalmente, com um mundo que parece se descompor, progressivamente. A produção incessante de objetos elevados ao lugar mais alto do mercado - o zênite - de modo insaciável e o seu destino inexorável, o de dejetos. A serviço do consumo, a ciência e a tecnologia não cessam de produzir o apagamento da subjetividade, como aponta Monique Amirault (2008, p. 22):

Apesar do bem que a ciência pode nos trazer, hoje ela está a serviço não mais do sujeito, que apaga, e sim do consumidor, que instrumenta. Mesmo assim, os objetos surgidos dessa ciência são desejados, levando a modos de gozar estandardizados, pela via de um mercantilismo do qual o homem é servo, embora lhe seja possível crer que aí encontra sua liberdade. Tudo lhe é oferecido para que ele "dê prazer a si mesmo". (Grifo da autora)

$\mathrm{Na}$ lógica do mercado, a criança aparece como consumidor privilegiado. Confrontada, muito cedo, às marcas, etiquetas, mensagens publicitárias, ela parece não poder viver sem os objetos comuns, chegando a quase desaparecer na massificação dos objetos. Nesse sentido, ela pode ser desembaraçada do seu valor de objeto precioso e ocupar o lugar de objeto a liberado, tornando-se mais um objeto entre a multiplicidade de objetos produzidos ao infinito no mercado. Amirault (2008) refere-se a um site que apresenta um bebê louro de olhos azuis para um banco de esperma dinamarquês Cryos e propõe pequenos vikings ao preço de 112 euros cada lâmina, com o slogan: "Parabéns, é um viking".

Lacan (1968), na "Nota sobre a criança", refere-se ao sintoma da criança como o que pode responder ao par familiar ou ao objeto do fantasma materno. Ele aponta que a criança tanto pode ser colocada no lugar de substituto fálico para os pais, quanto ser posta no lugar de objeto. Consumidor em potencial na sociedade de consumo, a criança é reduzida a objeto, esvaziada de subjetividade e condenada a sucumbir como objeto-dejeto da miséria da sociedade globalizada?

Segundo Brousse (2008), vive-se uma orientação para o desenvolvimento dos objetos, enunciados por Lacan pelo neologismo latusas. A 
produção em massa de objetos leva a empurrá-los para o destino de lixo, que tem seu lugar na contemporaneidade, não pelo fato de seres humanos serem tomados como objetos, pois eles sempre assim foram colocados. A novidade é o lugar de objetos/dejetos que passam a ser assumir. Em função do imperativo de gozar a qualquer custo do objeto, surge a idéia de que só pode haver satisfação no objeto, o que está em desacordo com a proposição da psicanálise de que as tentativas de saturar o desejo com o objeto estão condenadas a fracassar.

\section{O IMPERATIVO DO CONSUMO NA SOCIEDADE GLOBALIZADA}

É importante situar a psicanálise, em relação ao mundo contemporâneo. Há algum tempo, busca-se um suporte conceitual que dê legibilidade às transformações em que vivemos. Fala-se de Pós-modernidade (Lyotard), Hipermodernidade (Lipovetsky), Alta Modernidade (Guiddens) ou Modernidade Líqüida (Baumann).

O processo de globalização, na chamada modernidade tardia, originou um tipo de mudança estrutural que transformou a sociedade moderna, a partir da metade do século XX. Declinaram velhas identidades estabilizadas, o que fez surgir uma verdadeira crise de identidade, em função da multiplicidade dos sistemas de fragmentação e representações culturais. Representações foram dissolvidas, relações envelheceram, se desmancharam. As representações e as relações parecem se diluir, tal como preconizou Marx, ao afirmar: "Tudo o que era sólido se desmancha no ar, tudo o que era sagrado é profanado, e as pessoas são finalmente forçadas a encarar com serenidade sua posição social e suas relações recíprocas" (MARX; ENGELS, 1848, s/p.).

Segundo Hall (1998), o mundo denominado moderno é marcado pela fragmentação de velhas identidades estabilizadoras que declinaram. Deslocaram-se as estruturas e processos centrais das sociedades modernas que abalaram antigos quadros de referência. As transformações de tempo e espaço provocam indefinições e descontinuidades. A estrutura se viu deslocada e houve a substituição do centro para a pluralidade de espaços de poder. Tal política de fragmentação acabou por levar à pluralização das identidades. Para este autor, o processo no qual se projetam as identidades culturais tornou-se provisório, variável e problemático.

De acordo com Giddens (2003), vivemos uma era que caminha sob o impacto da ciência, da tecnologia e da racionalidade. Assiste-se ao 
mundo em descontrole cada vez maior. A inovação, cada vez mais freqüente, caminha junto ao risco e à incerteza. A idéia de risco refere-se aos infortúnios avaliados a partir das possibilidades futuras. Assim, viver no mundo globalizado significa enfrentar a diversidade de situações de risco.

Para Bauman (2005), na globalização, o Estado não tem mais o poder ou o desejo de manter uma união sólida com a nação. O que é da nação está aberto ao capital global e são derrubadas as barreiras ao fluxo das finanças internacionais. Ao transferir o capital aos mercados globais, há menos necessidade de reserva e fervor patriótico. O patriotismo foi transferido para as forças do mercado, o direito econômico ficou fora das mãos do Estado, os direitos políticos foram limitados e circunscritos ao pensamento do livre mercado neoliberal desregulado. Quanto aos direitos sociais, foram substituídos pelo dever do cuidado consigo mesmo. Como conseqüência, flutua-se em um espaço pouco definido, no qual a fase sólida da modernidade foi substituída pela fase fluida. $\mathrm{O}$ ambiente fluido leva ao não-saber o que esperar e vive-se num mundo esvaziado de valores, que se finge serem duradouros.

A civilização, na era da globalização, apresenta-se fragmentada, dispersa, não-localizada. $\mathrm{Na}$ era do capitalismo globalizado, estamos na ilusão da conquista virtual pretensamente ilimitada, espaço de desregulações em que reina a incerteza e não se encontra certeza, os mercados comuns parecem procurar um significante mestre e não o encontram.

Enquanto as sociedades ditas modernas, em sua fase inicial, eram caracterizadas por centrar-se na produção, engajando seus membros como produtores, nas sociedades denominadas supra-modernas, pós-modernas ou hipermodernas, engajam-se os seus membros na condição de consumidores. A transformação da sociedade moderna de produtores para a sociedade de consumo faz com que os sujeitos sejam transformados, ao mesmo tempo, em produtores de mercadorias e nas próprias mercadorias, passando a ser comandados pela lógica do "mercado" (BAUMAN, 1999; 2008).

Bauman (2008) salienta, ainda, que a sociedade de consumidores distingue-se pela reconstrução das relações à semelhança das relações entre os consumidores e os produtos a serem consumidos. $\mathrm{O}$ mundo fica dividido entre o sujeito consumidor e o objeto a ser consumido, com a transformação do consumidor em mercadoria a ser consumida. A coisificação do consumidor promove sua dissolução enquanto o sujeito, o que leva Bauman a falar de fetichismo da subjetividade. 
a "subjetividade" dos consumidores é feita de opções de compra - opções assumidas pelo sujeito e seus potenciais compradores; sua descrição adquire a forma de uma lista de compras. O que se supõe ser a materialização da verdade interior do self é uma idealização dos traços imateriais "objetificados" - das escolhas do consumidor. (BAUMAN, 2008, p. 24. Grifo do autor)

A ascensão dos objetos de consumo passou a regular as relações entre os semelhantes. As relações se coisificaram e os humanos foram reduzidos aos objetos. A produção maciça de objetos e sua constante desvalorização levam a uma estratégia de empuxo ao hiperconsumo e a uma conseqüente fabricação de lixos, de dejetos. Ao opor consumidores em potencial aos não-consumidores, coloca-se estes últimos na condição de inúteis, não porque estejam desempregados, mas porque não podem consumir. Deles nada se poderá esperar ou precisar, pois são indesejáveis e excluídos das sociedades humanas, puro lixo, meros dejetos, rebotalho da sociedade de consumo, como argumenta Bauman (2008).

Segundo Laurent (2007), depois do fim da Primeira Guerra Mundial, o mundo do pensamento foi tomado pelo sentimento de inutilidade da civilização. Se o sujeito tratava sua angústia antes da Segunda Guerra Mundial com sonhos de restauração totalitários, no pós-Segunda Guerra Mundial, o sujeito tratou de se abrigar dos novos significantes mestres que emergiram. Com a ascensão do mercado comum, houve a crença na extensão do universal autorizado pelo tratamento científico da civilização. Tal crença, segundo Laurent, negligenciou o retorno do gozo, o que não deixou de ter efeitos de práticas segregacionistas.

Laurent (2007) argumenta, ainda, que, com a desqualificação dos antigos ideais, surgiu um verdadeiro colapso no campo das identificações. A civilização fragmentária, dispersa e inconsistente leva à lógica da nãototalização. Sem um Deus para acreditar, o sujeito busca o êxtase ou a overdose, na civilização da "entrega para a morte", desde o matar-se de trabalhar, correr riscos nos esportes radicais, em vários gêneros de apetite pela ou gozar da própria morte.

Lipovetsky (2005) discute o processo de individualismo contemporâneo, enfatizando o fascínio pelo nada, no qual as formas de aniquilação assumem dimensões a ponto de que o deserto é a paisagem geográfica que designa o vazio no qual estão imersos os sujeitos. Com o desmoronamento dos ideais, surgem a estética de objetividade e a frieza que permite a aceleração das experimentações propícias às inovações da era capitalista globalizada. Como conseqüência, tem-se a despolitização e o desinteresse pela res publica 
e um hiperinvestimento no espaço privado, com a substituição do homo politicus pelo homo psycologicus. A falta de engajamento nas questões coletivas, marca da era do vazio, convive com o narcisismo e o hedonismo exacerbados. No campo do dever, também surgiram mudanças, de acordo com Lipovetsky (2005). Na civilização consumista, o Bem se transforma em bem-estar. Há uma sobreposição da felicidade à moral, dos prazeres à proibição, da fascinação ao dever. O desejo, outrora refreado, proibido, é antes exacerbado ao extremo. $\mathrm{Na}$ era do "basta querer para ser feliz", as obrigações morais foram substituídas pelo dever de felicidade. São legitimados os prazeres, os excessos, o conforto: "A sedução tomou o lugar do dever, o bem-estar tornouse Deus e a publicidade é seu profeta" (LIPOVETSKY, 2005, p. 31).

O dever que se escrevia em letras maiúsculas foi minimizado, que era severo e está organizado em shows recreativos, que ordenava submissão incondicional do desejo à lei foi reconciliado com o prazer. $\mathrm{O}$ dever cedeu lugar ao serás feliz, pois o declínio dos ideais foi acompanhado por exigências de gozo.

Para Eric Laurent (2007), no hedonismo de massa não há dificuldades para se manter nos limites do princípio do prazer, o que pode levar a subestimar a verdadeira natureza do supereu, sua exigência pulsional e poder ilimitado, num estado de civilização em que a pulsão revela ainda mais sua face mortal. A cultura assume aspectos superegóicos, o que impulsiona os sujeitos a se orientar em busca do gozo, um menos em relação aos ideais e um conseqüente mais de gozar, o que pode levar a fazer desaparecer a particularidade do sintoma. A visão hedonista do mundo apóia o império no acesso ao gozo para todos. Maximizar o gozo está ao alcance de cada um, mas o sujeito pode dizer não para o impulso a gozar que impede de emergir a particularidade do sintoma.

Se, em 1930, Freud acentuou a renúncia ao gozo com o trabalho, atualmente é com o excesso de trabalho que se pode obter os bens oferecidos pelo mercado. Para gozar dos bens materiais produzidos ao infinito, é imperativo se exceder no trabalho, até se matar de tanto trabalhar, pois é imperativo se submeter às exigências do mercado. O excesso de produção dos objetos de consumo exerce fascínio pela promessa de satisfação plena, de gozo generalizado. 


\section{EDUCAR PARA O CONSUMO?}

Pode-se pensar nos efeitos dessas fragmentação, dispersão e fluidez na educação das crianças nas sociedades capitalistas. Com o desenvolvimento do capitalismo, o tempo das crianças e suas atividades foram colonizados em função da realidade social e econômica, fazendo com que elas se encaminhem para os seus novos locais de "trabalho".

Anny Cordiè (1996) assinala que, nas sociedades ocidentais, o dinheiro, a posse de bens e o poder acabam se constituindo em ideais e valores que todos devem almejar. Ancorados em ideais narcísicos, visam a manter a ilusão de completude, de júbilo e gozo. É nessa via que a idéia de sucesso escolar ocupa um lugar proeminente na vida de crianças, pais, professores e governantes. Ser bem-sucedido na escola, assim, ocupa a perspectiva do ter acesso irrestrito ao consumo de bens.

Regido pela lógica do ter, o sujeito poderá ser considerado alguém, possuindo o poder e o dinheiro que indicam o alcance da felicidade absoluta, o acesso aos bens de consumo e bem-estar que ocupam o lugar do Bem supremo? A metamorfose do bem, nessa óptica, se situa entre o acesso aos bens de consumo e o ideal narcísico de bem-estar.

Crianças e adultos tornam-se parceiros na construção de mundo em que vivemos, mesmo que as primeiras estejam historicamente invisibilizadas pela definição social de que são "passivo" ou custo social. A infância legitima-se, assim, como posição de pouca importância da criança nas políticas públicas e repartição das riquezas socialmente geradas, por meio do processo cultural de menorização ou familiarização.

Segundo a lógica de produção capitalista, crianças são coadjuvantes dos adultos, se preparam, pelo trabalho escolar, para assumir seu lugar eventual de trabalhador e cidadão. Mudanças ocorrentes na consolidação do capitalismo introduzem nova relação entre produção e consumo e a preponderância entre valores de troca e valores de uso. Vê-se, portanto, numa era do consumo que se exacerba, um novo lugar para a infância, que passa a se situar em nova efetividade social.

$\mathrm{Na}$ lógica capitalista de todos iguais perante o consumo, a escola declina de lei educativa, impondo dessimetria entre educador e educando. A mestria ocupa outro lugar na transmissão do saber. A ética da globalização conecta homens por intermédio dos meios de comunicação e evidencia a solidão de cada um. A televisão transforma estranhos em figuras íntimas, elimina limites entre público e privado, promove a "banalização do mal”, reduz a violência a espetáculo de luzes e efeitos especiais. 
Hannah Arendt (2007) refere-se ao desaparecimento da autoridade, à perda da tradição e ao distanciamento do alicerce do passado. Quanto à crise na educação, destaca alguns pressupostos básicos: a crença em uma autonomia das crianças, a quem se deve permitir governar; a emancipação, por parte do professor, do saber competente na matéria ensinada; a substituição do saber pelo fazer. A perda da autoridade não deixa de ter conseqüências: "A autoridade foi recusada pelos adultos, e isso somente pode significar uma coisa: que os adultos se recusam a assumir a responsabilidade pelo mundo no qual trouxeram as crianças" (ARENDT, 2007, p. 240).

A autora salienta também ser necessário compreender que a escola deve ensinar aos alunos sobre o mundo como ele é e não instruir sobre a arte de viver, não se deveria tratar crianças como se fossem adultos, não se deve educar sem ensinar, pois uma educação sem aprendizagem é vazia.

Ruth Cohen (2006) refere-se a Chomsky, que entende que o saber se vincula diretamente à busca de lucro e que os atuais governos, ditos democráticos, exercem política de proteção da propriedade privada em que a força de mercado globalizada, rege a vida dos cidadãos. A versão contemporânea da lógica do para todos, característica da globalização, leva a vários tipos de segregação. O poder tecnológico e científico empregado na transmissão de valores de uma sociedade é sempre desigual. Assim, democracia e capitalismo - em conexão com o saber globalizado - pressupõem um universal democrático, contraditório, que promove a segregação. Assim, pode-se pensar o fracasso escolar articulado aos ideais impostos pela sociedade do consumo, na sociedade atual.

Se o fracasso escolar surge como um dos sintomas do mal-estar na infância na contemporaneidade, pode-se pensar quais as conseqüências da educação que se baseia na suposta igualdade entre adultos e crianças, regidos pela ética do consumo. Negação da diferença, que, longe de garantir a igualdade, não faz mais do que garantir a exclusão. Ao ser difundida a promessa de um alcance do prazer a qualquer preço, em que tudo é permitido, qual o preço que se paga em relação ao além do princípio do prazer?

Segundo Cohen (2006), ao se identificar como o Outro do saber, o educador pode sustentar o imperativo capitalista como forma de guiar os seus alunos: "Estudar é forma de usufruir melhor os bens do futuro". Tal demanda é atendida por algumas escolas, pois instituições são procuradas como uma espécie de passaporte para a universidade, mesmo a 
preço muito alto a ser pago pelo aluno. Existem instituições privadas de ensino que obedecem à ética que promove políticas educacionais segregacionistas, convidando os alunos que não passam de ano a se retirar da escola. Assim, o fracasso escolar que expulsa a criança da escola gera a exclusão subjetiva, porque, como objeto, ela é posta fora do discurso da educação.

As promessas de um gozo ilimitado promovem a ilusão de que é possível ter tudo ao alcance de qualquer um. Tenta-se saturar o desejo com a promessa de possuir o saber como se fosse um objeto comum, à disposição no mercado. Cohen (2006) lembra também que a sobrecarga de informações provoca demanda de aceleração, que impõe a necessidade de nivelar os sujeitos pelo consumo, como se depreende da proliferação de projetos especiais destinados a torná-lo professor. Os professores, mal começam a aprender a lidar com um projeto, este já se torna obsoleto e o império da efemeridade, a lógica do gosto pela novidade, caracteriza a nossa líqüida civilização, invadindo a chamada "formação de professores". As causas do fracasso escolar estariam relacionadas à demanda do Outro contemporâneo, seja a escola, a família ou a política. As tensões inconscientes em jogo nos processos de aprendizagem podem ser entendidas como respostas às demandas do tecido social (representado por escola, família, Estado).

Se a lógica capitalista tende a igualar os sujeitos à mera condição de rebotalhos do tecido social, faz-se necessário ao educador se recusar a participar do imperativo do consumo que ordena o gozo absoluto, desmedido e insano que se impõe na educação regida pela lógica do mercado.

Cohen (2006) lembra também que o educador pode ser confrontado tanto com o não-saber dos seus alunos como com o excesso de saber. A criança pode ocupar o lugar de objeto para o professor, encarnando o resíduo recalcado da mestria situado sob o saber-fazer do Outro. Ao deixar a criança presa no lugar de um produto que serve de sustentação para o Outro, faz-se dela um excesso, um resto ou dejeto, sobre o qual a dinâmica capitalista nada quer saber.

Segundo a autora citada, a educação, ao vestir a máscara de saber totalizante, traduz-se em uma promessa de gozo, como se fosse algo que, um dia, livraria o aluno da impossibilidade de um saber "todo", por meio de imperativos do tipo "estude para gozar melhor o futuro". O professor pode encarnar o Outro absoluto do saber, identificado a um perigoso ideal, mostrando à criança um lugar de insuficiência e debilidade. O educador deve levar em conta a possibilidade de se tornar um agente de 
reprodução de neuroses, pois a criança pode estar submetida à economia e à política de um discurso pedagógico que a inscreve no lugar de objeto. O que pode ser observado em casos em que a política educacional, em nome do poder da ciência, usa e abusa de métodos educacionais arrojados que fazem das crianças cobaias de suas experimentações.

Se, de um lado, assiste-se à queda de ideais, por outro, há uma proliferação deles. A sobrecarga de ideais e de valores hedonistas, em que se postula uma ilusória ausência de mal-estar aumenta, a tendência à frustração e à decepção, como sustenta Lipovetsky (2007, p. 6):

Quando se põe em destaque um fantasioso conceito de "carência zero" generalizante, como é possível escapar do aumento da decepção? Quanto mais os imperativos do bem-estar e do bem-viver são fixados como meta imprescindível, mais intransitáveis se tornam as alamedas do desapontamento.

A queda dos ideais de outrora e as promessas totalizadoras de um futuro no qual, pretensamente, poder-se-ia abolir a falta localiza a "crise na educação" na ausência de autoridade, nos ideais de igualdade e negação das diferenças entre o adulto e a criança, na desqualificação do saber do educador e na imposição de gozo no campo educativo. Os efeitos segregativos do discurso da ciência e da tecnologia sustentados pelo discurso capitalista fazem-se sentir no campo da educação por meio da massificação do ensino, o que pode levar ao apagamento da subjetividade da criança e do adulto que por ela deveria se responsabilizar.

Para Barros (2008), a criança recebe a transmissão do legado da miséria dos adultos e, caso a miséria dos adultos não se refira à castração, essa transmissão é dificultada e pode levar a criança a sucumbir como objeto-dejeto. Nesse sentido, é necessário fazer entrar em jogo a lógica da castração como modo de recusa ao gozo generalizado ofertado pela lógica mercantilista da sociedade atual.

\section{A INDIFERENÇA PURA NO DESERTO DO REAL ATUAL}

Lipovetsky (2005) enfatiza não a angústia, mas o tédio e a indiferença em decorrência do desmoronamento dos ideais. O deserto de significações não se traduz pela revolta, o grito ou o desafio da comunicação. Diante do declínio da autoridade do educador, cuja palavra foi dessacralizada, tornando-se banal e em pé de igualdade com a palavra da mídia, o ensino se transformou em uma máquina neutralizada pela apatia escolar, 
feita de atenção dispersa e de ceticismo desenvolto em relação ao saber. Surgiu o desafeto pelo saber, que parece ser mais significativo que o tédio dos estudantes.

A escola assemelha-se ao deserto onde jovens vegetam sem motivação ou interesse. Assim, é preciso inovar a qualquer preço, cada vez mais liberalismo, participação, pesquisa pedagógica. Mas quanto mais a escola dá ouvidos aos alunos, mais eles abandonam esse lugar vazio. Desapareceram as greves após 1968, a escola transformou-se em um corpo mumificado e os professores compõem um corpo fatigado e incapaz de insuflar vida.

Freud (1910), no texto "Contribuições para uma discussão acerca do suicídio", coloca a escola no lugar traumático com que se confrontam os adolescentes. Alerta que a escola deveria não conseguir mais que impelir os alunos ao suicídio, promovendo-lhes o desejo de viver. Caso a escola não possa adjudicar-se o caráter de vida, ela não poderá barrar a pulsão de morte. Assim, o deserto em que se constitui a escola nos tempos atuais parece não barrar o gozo mortífero, e a acentuação das diferenças não cessa de produzir a indiferença ou o gozo autístico que impede o laço com o semelhante. O afeto do tédio surge diante do semsentido em que parece se constituir o espaço escolar, pois, diante da proliferação de sentidos, faz falta buscar um acesso possível ao saber.

\section{O SOFRIMENTO NA INFÂNCIA - A CRIANÇA VÍTIMA GENERALIZADA}

$\mathrm{Na}$ alocução sobre as psicoses na infância, Lacan decreta: "Havemos de destacar pelo termo criança generalizado a conseqüência disso" (1968, p. 367). E acrescenta: "Acabei acreditando, veja só, neste declínio da minha vida (...) que não existe gente grande” (ibidem, p. 367). $\mathrm{Na}$ denúncia lacaniana de que vivemos a era da infância generalizada, ele apontou não haver pessoas grandes, pessoas dispostas a cuidar das crianças, acolhendo com presteza as suas necessidades. Laurent (2007) destaca uma verdadeira epidemia de gozo mortífero, em que se delineia o estranho lugar ocupado pela criança vítima. Refere-se a atos de pedofilia, prostituição e práticas incestuosas cometidas contra as crianças pelos próprios pais.

De pretensa majestade, a criança ocupa o lugar de vítima e os comportamentos irracionais de quem deveria cuidar da criança provocam impotência na assistência social e na família. A epidemia de gozo mor- 
tífero que surge como expressão da pulsão de morte aponta para o forado-sentido. Para tentar verificar o lugar da criança vitimizada, faz-se necessário ouvir as crianças. Para Laurent, trata-se de vitimizar duplamente a criança.

Em seu entendimento, Laurent considera que o lugar da criança vitimizada é o inverso do estado dado à subjetividade, que é a de ser um sujeito que corre riscos. Cada risco é apresentado como uma espécie de cálculo e sem sentido sob um nível estrito de igualdade, mas o risco generalizado e as vítimas que ele engendra apagam a dimensão da responsabilidade em nome do risco, que acaba se constituindo em vetor de subjetividade vazia e, no lugar da questão, o risco. A posição da psicanálise, pelo contrário, é buscar, a partir de uma vítima, a chance de criar um sujeito responsável por seu gozo.

É nesse sentido que se pode retomar a posição da criança como objeto a liberado, produzido. No texto "Nota sobre a criança", Lacan (1969) afirma que a criança pode realizar a presença de objeto na fantasia materna, o que a deixaria exposta a todas as capturas fantasísticas. Ao se tornar o objeto da mãe, não teria outra função senão a de revelar a verdade desse objeto.

Entender a criança como objeto é entendê-la de outro modo que não como revestida por uma significação fálica. Na perspectiva freudiana, a criança era vista como substituto do falo e, no lugar do ideal do eu parental, o lugar de sua Majestade, o bebê, revivescência do narcisismo parental. Na perspectiva dos psicanalistas que se ocuparam da psicanálise de crianças, iniciou-se uma teorização sobre o lugar de objeto (parcial, transicional) ocupado pela criança. Ao entendê-la como objeto, enfatizase o lugar que a criança ocupa em relação ao gozo, à satisfação pulsional. A ênfase não é a criança capturada como ideal, mas como objeto do qual se pode gozar.

No seminário "De um Outro ao outro", Lacan (1968-9) denuncia a criança como objeto a liberado, produzido. Nesse sentido, ele aponta a criança não só como objeto a da fantasia materna, mas como objeto de gozo da família, da civilização, o que não é sem conseqüências para a subjetividade da criança.

$\mathrm{Na}$ era do hedonismo mortífero, em que se trata de gozar a qualquer custo, as famílias, que deveriam se ocupar da educação das crianças, não se apoiando na falta que causa o desejo, não oferecem a transmissão irredutível apoiada na relação com um desejo não anônimo. Ao expor a criança às capturas fantasísticas pela impossibilidade de oferecer uma 
identificação ideal, sem mediação da falta materna e da Lei do desejo do pai, não resta outra saída senão manter a criança como vítima do gozo mortífero da infância generalizada que responde ao imperativo hedonista da sociedade de consumo.

Se o que está em jogo no drama das famílias é a liberação do objeto $a$, cabe indagar como oferecer à criança outro lugar que não o de objeto do gozo mortífero. Para Laurent (2007), o sintoma depende da civilização. Ele alerta que foi necessário o declínio do pai para que o parricídio deixasse de interessar e para que a criança maltratada tomasse a frente da cena. Com o declínio da imago paterna, o crime atual não é mais o parricídio, mas o abuso, a pedofilia, o infanticídio, a vitimização da criança. Se há um resto não-contabilizável na produção da mais-valia, esse retorno de gozo mortífero que vitimiza a criança é sintoma do mal-estar na civilização do consumo globalizado. Se é proibido proibir, se é imperativo o prazer, como permitir um freio ao gozo que possibilite o desejo?

\section{ESCUTAR O SINTOMA}

Num mundo tão permissivo, o que caberia à psicanálise? Podese dizer, com Lacan (1968), que é próprio da formação humana pôr um freio ao gozo. Pode-se dizer não ao impulso ao hedonismo generalizado, não permitindo que o "pronto para gozar generalizado" possa impedir de escutar a particularidade do sintoma. Assim, pode-se intervir nos lugares em que os sintomas contemporâneos são recolhidos.

Para Laurent (2007), o analista cidadão pode intervir na polis com o seu dizer silencioso, que implica tomar partido de maneira ativa, silenciar a dinâmica de grupo que rodeia a organização social. $O$ analista deve ser sensível às formas de segregação, contribuindo para que não se esqueça a particularidade de cada um, seja em nome da universalidade ou de qualquer outro universal.

Concluo com uma indicação preciosa de Hanna Arendt (2007, p. 247) que aponta a saída pelo amor à criança, um modo de o gozo condescender ao desejo:

A educação é, também, onde decidimos se amamos nossas crianças o bastante para não expulsá-las de nosso mundo e abandoná-las a seus próprios recursos, e tampouco arrancar de suas mãos a oportunidade de empreender alguma coisa nova e imprevista para nós, preparando-as em vez disso com antecedência para a tarefa de renovar um mundo comum. 


\section{REFERÊNCIAS}

AFLALO, A. Discurso capitalista. O discurso peste. Scilicet. Os objetos a na experiência psicanalítica. Rio de Janeiro: Contra Capa, 2008. p. 83-85.

AMIRAULT, M. Aletosfera. Últimas notícias da aletosfera. Scilicet. Os objetos a na experiência psicanalítica. Rio de Janeiro: Contra Capa, 2008. p. 22-24.

ARENDT, H. Entre o passado e o futuro. Trad. Mauro W. Barbosa. 6 ed. São Paulo: Perspectiva, 2007.

BARROS, M. R. C. R. Criança. Os objetos a na experiência psicanalítica. Rio de Janeiro: Contra Capa, 2008. p. 63-67.

BAUMAN, Z. Identidade. Rio de Janeiro: Jorge Zahar, 2005.

BROUSSE, M. H. Objetos soletrados no corpo. Arquivos da biblioteca 5. Rio de Janeiro: Escola Brasileira de Psicanálise, jun. 2008.

CORDIÉ, A. Os atrasados não existem. Psicanálise de crianças com fracasso escolar. Trad. Sônia Flach; Marta D’agord. Porto Alegre: Artes Médicas, 1996.

COHEN, R. H. P. A lógica do fracasso escolar. Psicanálise \& Educação. Rio de Janeiro: Contra Capa, 2006.

FINK, B. O sujeito lacaniano entre linguagem e gozo. Trad. Maria de Lourdes Sette Câmara. Rio de Janeiro: Jorge Zahar, 1988.

FREUD, S. (1910). Contribuições para uma discussão acerca do suicídio. Edição Standard Brasileira das Obras Psicológicas Completas de Sigmund Freud. Trad. Jayme Salomão. Rio de Janeiro: Imago, 1970. p. 217-219.

GUIDDENS, A. Mundo em descontrole: o que a globalização está fazendo de nós? Rio de Janeiro: Record, 2003.

HALL, Stuart. A identidade cultural na pós-modernidade. Tradução Tomaz Tadeu da Silva e Guacira Lopes Louro. Rio de Janeiro: DP\&A, 1998.

KAUFFMAN, P. Dicionário enciclopédico de Psicanálise. O legado de Freud e Lacan. Trad. Vera Ribeiro, Maria Luiza X. de A. Borges; Consultoria: Marco Antonio Jorge. Rio de Janeiro: Jorge Zahar, 1996.

LACAN, J. (1968-9). O seminário, livro 16. De um Outro ao outro. Trad. Vera Ribeiro. Rio de Janeiro: Jorge Zahar, 2008.

LACAN, J. (1968). Alocução sobre as psicoses da criança. Outros escritos. Trad. Vera Ribeiro. Rio de Janeiro: Jorge Zahar, 2003. p. 361-368.

LACAN, J. (1969). Nota sobre a criança. Outros escritos. Trad. Vera Ribeiro. Rio de Janeiro: Jorge Zahar, 2003. p. 369-370.

LACAN, J. (1970). Radiofonia. Outros escritos. Trad. Vera Ribeiro. Rio de Janeiro: Jorge Zahar, 2003. p. 400-447.

LAURENT, E. A sociedade do sintoma. Trad. Vera Avellar Ribeiro. Rio de Janeiro: Contra Capa, 2007.

LIPOVETSKY, G. Os tempos hipermodernos. Trad. Mário Vilela. São Paulo: Barcarola, 2004.

LIPOVETSKY, G. A era do vazio. Ensaios sobre o individualismo contemporâneo. Trad. Terezinha Monteiro Deutsch. Barueri: Manole, 2005.

LIPOVETSKY, G. A sociedade pós-moralista. O crepúsculo do dever e a ética indolor dos novos tempos democráticos. Trad. Armando Braio Ara. Barueri: Manole, 2005.

LIPOVETSKY, G. A sociedade da decepção. Trad. Armando Braio Ara. Barueri: Manole, 2007.

MARX, Karl; ENGELS, Friedrich. Manifesto do Partido Comunista, 1848. Disponível em: 
<http://www.culturabrasil.pro.br/manifestocomunista.htm>. Acessado em: 21/09/2008. VIEIRA, M. A. A (hiper) modernidade lacaniana. Latusa. 9. Rio de Janeiro: Escola Brasileira de Psicanálise. Rio de Janeiro: Escola Brasileira de Psicanálise, p. 69-82.

ZIZEK, S. Bem-vindo ao deserto do real! Cinco ensaios sobre o 11 de setembro e datas relacionadas. Trad. Paulo César Castanheira. São Paulo: Boitempo, 2003.

Recebido: 30/09/2008

Aprovado: 01/10/2008

Contato:

Rua da Consolação, 930

Prédio 38

Consolação

São Paulo - SP

01302-090 